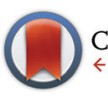

CrossMark \&lick for updates

Cite this: Dalton Trans., 2016, 45 10771

Received 10th April 2016,

Accepted 1st June 2016

DOI: 10.1039/c6dt01389a

www.rsc.org/dalton

\title{
2,6-Dipicolinoylbis( $\mathbf{N}, \mathbf{N}$-dialkylthioureas) as versatile building blocks for oligo- and polynuclear architectures $\uparrow$
}

\author{
H. H. Nguyen, ${ }^{\star a}$ J. J. Jegathesh, ${ }^{b}$ A. Takiden, ${ }^{\text {b D. Hauenstein, }}{ }^{\text {b C. T. Pham, }}{ }^{\text {b C. D. Le }}{ }^{a}$ \\ and U. Abram*b
}

\begin{abstract}
Similar reactions of 2,6-dipicolinoylbis $\left(\mathrm{N}, \mathrm{N}\right.$-diethylthiourea) $\left(\mathrm{H}_{2} \mathrm{~L}^{\mathrm{a}}\right)$ with: (i) $\mathrm{Ni}\left(\mathrm{NO}_{3}\right)_{2} \cdot 6 \mathrm{H}_{2} \mathrm{O}$, (ii) a mixture of $\mathrm{Ni}\left(\mathrm{NO}_{3}\right)_{2} \cdot 6 \mathrm{H}_{2} \mathrm{O}$ and $\mathrm{AgNO}_{3}$, (iii) a mixture of $\mathrm{Ni}(\mathrm{OAC})_{2} \cdot 4 \mathrm{H}_{2} \mathrm{O}$ and $\mathrm{PrCl}_{3} \cdot 7 \mathrm{H}_{2} \mathrm{O}$ and (iv) a mixture of $\mathrm{Ni}(\mathrm{OAC})_{2} \cdot 4 \mathrm{H}_{2} \mathrm{O}$ and $\mathrm{BaCl}_{2} \cdot 2 \mathrm{H}_{2} \mathrm{O}$ give the binuclear complex $\left[\mathrm{Ni}_{2}\left(\mathrm{~L}^{\mathrm{a}}\right)_{2}(\mathrm{MeOH})\left(\mathrm{H}_{2} \mathrm{O}\right)\right]$, the polymeric compound $\left[\mathrm{NiAg}_{2}\left(\mathrm{~L}^{\mathrm{a}}\right)_{2}\right]_{\infty}$, and the heterobimetallic complexes $\left[\mathrm{Ni}{ }_{2} \mathrm{Pr}\left(\mathrm{L}^{\mathrm{a}}\right)_{2}(\mathrm{OAC})_{3}\right]$ and $\left[\mathrm{Ni}_{2} \mathrm{Ba}\left(\mathrm{L}^{\mathrm{a}}\right)_{3}\right]$, respectively. The obtained assemblies can be used for the build up of supramolecular polymers by means of weak and medium intermolecular interactions. Two prototype examples of such compounds, which are derived

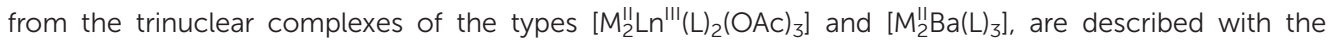
compounds $\left\{\left[\mathrm{Cu}_{2}^{\prime \prime} \mathrm{Dy} y^{\prime \prime \prime}\left(\mathrm{L}^{\mathrm{a}}\right)_{2}\left(\mathrm{p}-\mathrm{O}_{2} \mathrm{C}-\mathrm{C}_{6} \mathrm{H}_{4}-\mathrm{CO}_{2}\right)(\mathrm{MeOH})_{4}\right] \mathrm{Cl}\right\}_{\infty}$ and $\left[\mathrm{Mn}{ }_{2}^{\prime \prime} \mathrm{Ba}(\mathrm{MeOH})\left(\mathrm{L}^{\mathrm{b}}\right)_{3}\right]_{\infty}, \mathrm{H}_{2} \mathrm{~L}^{\mathrm{b}}=2,6$-dipicolinoylbis( $N, N$-morpholinoylthiourea).
\end{abstract}

\section{Introduction}

The structural chemistry of self-assembled oligonuclear coordination compounds, which is frequently referred to as supramolecular coordination chemistry, has found growing attention during recent years. This is due to the wide structural variety of such products and related opportunities for tailoring of novel compounds with unique chemical or physical properties, which make them interesting e.g., as molecular nanocontainers, catalysts, molecular magnets, or models for reactive centers in bioinorganic systems. ${ }^{1-9}$

Such assemblies are typically obtained in one-pot reactions by mixing soluble metal salts and ligands, which spontaneously self-assemble under formation of single, thermodynamically favoured products. ${ }^{1}$ Five favoured strategies, namely Stang's directional binding approach, ${ }^{10}$ Fujita's molecular panelling procedure, ${ }^{11}$ Raymond's symmetry-interaction method, ${ }^{12}$ Cotton's use of dimetallic building blocks, ${ }^{13}$ and Mirkin's weak-link approach, ${ }^{14}$ have been developed and

\footnotetext{
${ }^{a}$ Department of Chemistry, Hanoi University of Science, 19 Le Thanh Tong, Hanoi, Vietnam.E-mail: hhnguyen@vnu.edu.vn

${ }^{b}$ Institute of Chemistry and Biochemistry, Freie Universität Berlin, Fabeckstr. 34-36, D-14195 Berlin, Germany. E-mail: ulrich.abram@fu-berlin.de

$\dagger$ Electronic supplementary information (ESI) available: Ellipsoid representations of the molecular structures, tables with bond lengths and angles, optimized structure of compound 5. CCDC 1417138, 1417140, 1417141, 1469387 and 1469388. For ESI and crystallographic data in CIF or other electronic format see DOI: $10.1039 /$ c6dt01389a
}

widely used for the rational synthesis of aesthetic supramolecular coordination compounds with pre-determined shapes, sizes and functionalities. Representative structural topologies are molecular triangles or squares, ${ }^{15,16}$ or corresponding threedimensional units such as tetrahedral or octahedral cages. ${ }^{17,18}$ Due to the strict requirements of chemical information being encoded in the subunits, however, the selection of appropriate building blocks continues to be a challenge in the designing of large and complex coordination systems. The use of ligand systems containing 'hard' as well as 'soft' donor atoms helps to get control over the direction of the metal ions to distinct donor sites in mixed-metal systems. This shall be demonstrated with the structural chemistry of such compounds with extended aroyl- $N, N$-dialkylthioureas.

$N, N$-Dialkyl- $N$-benzoylthioureas are versatile chelators, which form stable complexes with a large number of transition metal ions. ${ }^{19,20}$ In most of the structurally characterized complexes, they act as bidentate $S, O$-monoanionic ligands (1, Fig. 1). ${ }^{21-23}$ This coordination mode has also been found for the extended tetraalkylisophthaloylbis(thioureas) in binuclear bis-chelates of the type 2 with $\mathrm{Cu}^{2+}, \mathrm{Ni}^{2+}, \mathrm{Zn}^{2+}, \mathrm{Co}^{2+}, \mathrm{Cd}^{2+}, \mathrm{Pt}^{2+}$ and $\mathrm{Pd}^{2+}$ ions, ${ }^{24-28}$ and in a binuclear tris-chelate of $\mathrm{In}^{3+} \cdot{ }^{29}$ Oxido-bridged, tetrameric rhenium(v) complexes (3) with tetraalkylisophthaloylbis(thioureas) establish molecular voids of considerable size. ${ }^{30}$

The simple replacement of the central phenylene ring between the two $S, O$-chelating units of 2 or 3 by units with potential nitrogen donor atoms should result in ligands with completely new coordination properties and the resulting 

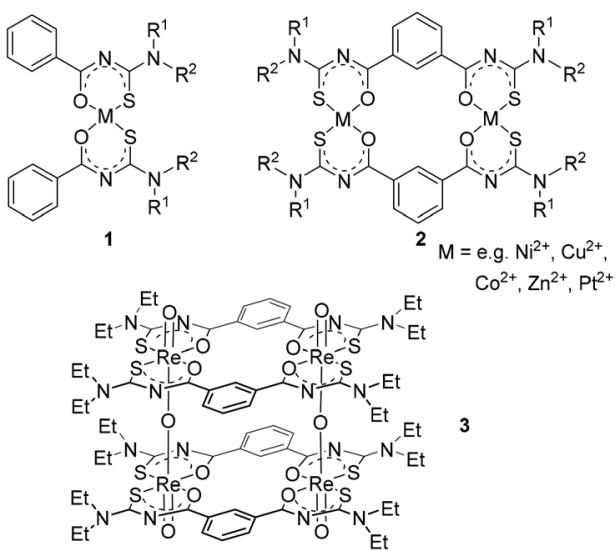

Fig. 1 Aroylthiourea chelates.<smiles>CCN(CC)C(=S)NC(=O)c1ccc(C(=O)NC(=S)N(CC)CC)[nH]1</smiles><smiles>[R]N([R])C(=S)NC(=O)c1cccc(C(=O)NC(=S)N([R])C)n1</smiles>

$H_{2} L^{a}: R^{1}, R^{2}=E t$

$H_{2} L^{b}: R^{1} R^{2}=$ Morph

Fig. 2 Heterocyclic-centered aroylthioureas.

complexes may be the fundament of a new class of heterometallic host-guest complexes. Recent attempts with the pyrrolecentered ligand 4 failed in this sense, since the central pyrrole ring did not deprotonate in corresponding bi- and tetranuclear oxidorhenium(v) complexes and the central $\mathrm{NH}$ functionalities only establish hydrogen bonds to guest solvent molecules. ${ }^{31}$ Attempts with corresponding 2,6-dipicolinoylbis $(\mathrm{N}, \mathrm{N}$-dialkylthioureas), $\mathbf{H}_{2} \mathbf{L}$ (Fig. 2), seem to be more promising. They possess, in addition to the 'hard' oxygen and the 'soft' sulfur donors, a 'borderline' base (in the sense of Pearson's acid base concept): ${ }^{32}$ the pyridine nitrogen atom. Suitable substitutions in their peripheries $\left(\mathrm{R}^{1}, \mathrm{R}^{2}\right)$ may allow further aggregation of the formed complexes. Surprisingly less is known about the coordination abilities of $\mathrm{H}_{2} \mathrm{~L}$ and only one polymeric $\mathrm{Ag}^{+}$ compound with exclusive $\mathrm{Ag}-\mathrm{S}$ coordination has hitherto been characterized structurally. ${ }^{33}$

\section{Results and discussion}

The structural versatility of the pyridine-centered aroylbis(thioureas) is best shown by some reactions of the simplest representative of these ligands, $\mathrm{H}_{2} \mathrm{~L}^{\mathrm{a}}$. An overview about the performed reactions and their products is presented in Scheme 1 . The corresponding reactions have been performed first with $1: 1: 1$ rations of the reactants. Later, the ratios were optimized with regard to those in the products obtained from the first (un-optimized) reactions.

\section{The $\mathrm{Ni}^{2+}$ complex with $\mathrm{H}_{2} \mathrm{~L}^{\mathrm{a}}$}

Already the common reaction of $\mathrm{H}_{2} \mathrm{~L}^{\mathrm{a}}$ with $\mathrm{Ni}\left(\mathrm{NO}_{3}\right)_{2} \cdot 6 \mathrm{H}_{2} \mathrm{O}$ does not result in the formation of a bimetallic bis-chelate similar to compound 2. Irrespective of the molar ratio between the reactants, a green solid precipitated from the acetone/ $\mathrm{MeOH}(1 / 1, v / v)$ reaction mixture. The ${ }^{1} \mathrm{H}$ NMR spectrum of the compound shows broad signals, which are typical for paramagnetic octahedral complexes of $\mathrm{Ni}^{2+}$. The IR spectrum shows a strong absorption at $1624 \mathrm{~cm}^{-1}$, which is in the typical region of the vibrations of uncoordinated $\mathrm{C}=\mathrm{O}$ groups in the monodentate $S$-bonded benzoylthiourea complexes, ${ }^{34,35}$ and much higher than those found in $S, O$-chelating benzoylthioureato complexes (around $1550 \mathrm{~cm}^{-1}$ ). ${ }^{21-23,36}$ Thus, the spectral data of $\mathbf{5}$ predict an unusual structure, which is clearly different from that of 2 .

The results of a structural analysis (Fig. 3) reveal that $\mathbf{5}$ is a dinuclear nickel complex with two $\left\{\mathrm{L}^{\text {a }}\right\}^{2-}$ ligands. Both nickel atoms are six-coordinate with distorted octahedral environments, but with different coordination modes. Ni1 is meridionally coordinated by two $\{\mathrm{O}, \mathrm{N}, \mathrm{N}\}$ donor sets, each of them belonging to one ligand and consisting of the carbonyl $\mathrm{O}$ atom of the first acylthiourea arm, the pyridine $\mathrm{N}$ atom, and the amide $\mathrm{N}$ atom of the second acylthiourea arm. The resulting distortions prevent the $S$ and $O$ atoms of the amidecoordinated ligand arms from further chelate formation, because they are bent out of plane. In contrast, the remaining two arms can coordinate with $\mathrm{Ni} 2$ in the 'usual' $S, O$-chelating mode. The axial positions of $\mathrm{Ni} 2$ are occupied by a $\mathrm{MeOH}$ and a $\mathrm{H}_{2} \mathrm{O}$ ligand.

The unusual structure of complex 5, particularly the fact that the coordination of the $\mathrm{Ni}^{2+}$ ion to the central pyridine ring seems to be preferred over the formation of $S, O$ chelates as being observed in the complexes $\mathbf{1}$ and 2, motivated us to DFT calculations in order to find an explanation. ${ }^{38}$ Thus, we calculated the overall energies for optimized geometries of complex 5 as well as for possible isomeric compounds. The results of the geometrical optimization obtained for compound $\mathbf{5}$ are in good agreement with the experimental data. The bond lengths differ by less than $0.09 \AA$ and the angles by less than $4^{\circ}$. A table with details of the experimental and calculated structural data is contained in the ESI. $\dagger$ On the basis of the good agreement between the experimental and calculated data for compound 5, we extended the calculations to the isomeric complexes $\mathbf{5}^{\prime} \mathbf{- 5} \mathbf{5}^{\prime \prime \prime}$ given in Fig. 4 in order to get information about stabilizing or destabilizing effects due to the modifications in the coordination sphere of the metal ions. A comparison of the electric energies of optimized structures of the $S, O$-coordinated isomers and complex 5 strongly suggests that the latter compound is by far the most stable in this series with a calculated energetic difference of more than $73 \mathrm{~kJ} \mathrm{~mol}^{-1}$ (Table 1).

The obviously favoured direction of the 'borderline acid' $\mathrm{Ni}^{2+}$ to the 'borderline base' pyridine (according to the Pear- 

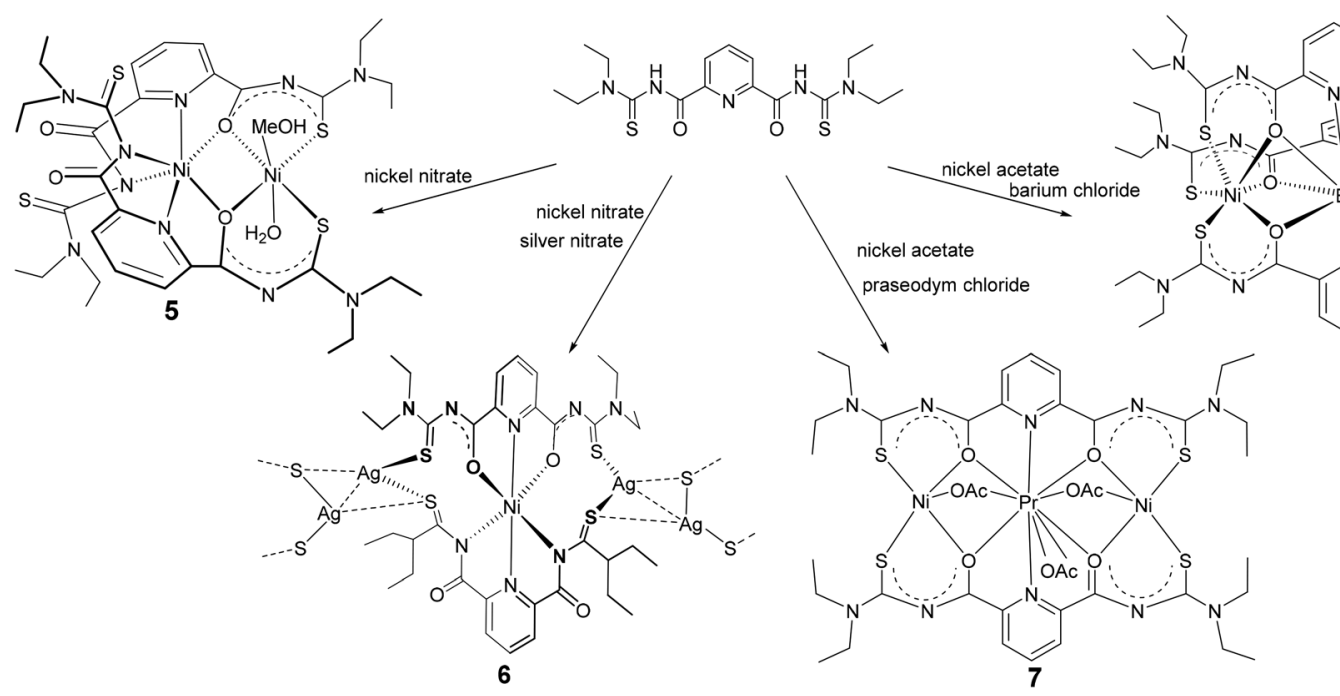

Scheme 1 Syntheses and compositions of the novel complexes with $\mathrm{H}_{2} \mathrm{~L}^{\mathrm{a}}$.

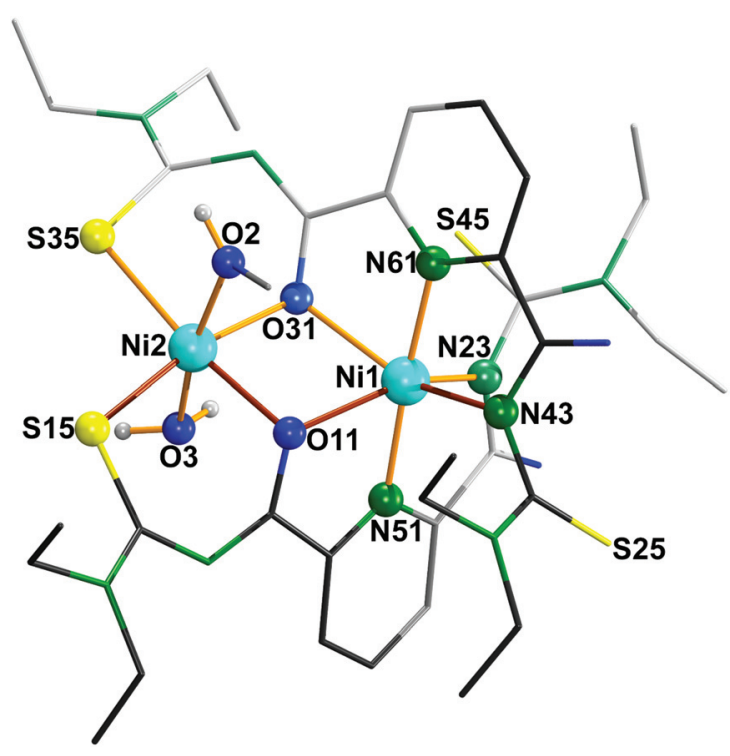

Fig. 3 Molecular structure of $\left[\mathrm{Ni}_{2}\left(\mathrm{~L}^{\mathrm{a}}\right)_{2}(\mathrm{MeOH})\left(\mathrm{H}_{2} \mathrm{O}\right)\right](5) .{ }^{37}$
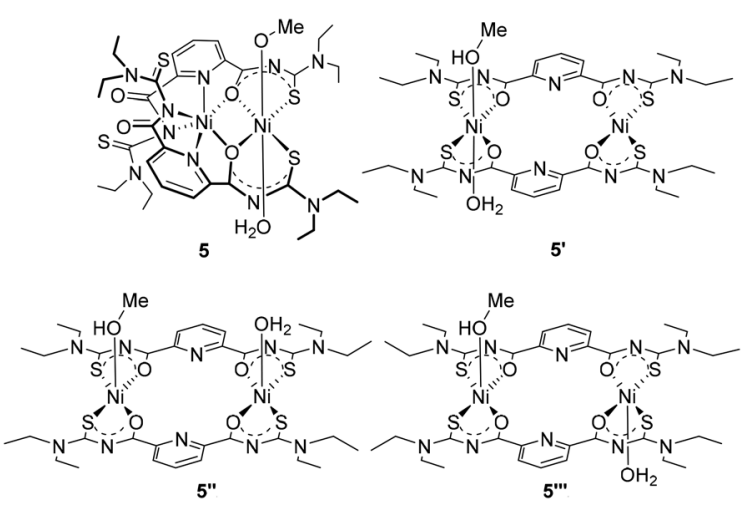

Fig. 4 Possible isomers of complex 5.
Table 1 Energies of optimized geometries of the isomers of complex 5

\begin{tabular}{lllc}
\hline Isomer & Spin state & $E$ (Hartree) & $\begin{array}{l}\text { Relative energy } \\
\left(\mathrm{kJ} \mathrm{mol}^{-1}\right)\end{array}$ \\
\hline $\mathbf{5}$ & Quintet & -4291.90416 & 0.00 \\
$\mathbf{5}^{\prime}$ & Triplet & -4291.85777 & 121.80 \\
$\mathbf{5}^{\prime \prime}$ & Quintet & -4291.86678 & 98.15 \\
$\mathbf{5}^{\prime \prime \prime}$ & Quintet & -4291.87631 & 73.14
\end{tabular}

son's concept) gave enough reason for ongoing experiments with 'softer' and 'harder' metal ions as competitors in such reactions.

\section{Mixed-metal $\mathrm{Ni}^{2+} / \mathrm{Ag}^{+}, \mathrm{Ni}^{2+} / \mathrm{Ba}^{2+}$ and $\mathrm{Ni}^{2+} / \mathrm{Pr}^{3+}$ complexes with $\mathbf{H}_{2} \mathbf{L}^{\mathrm{a}}$}

Attempts to use the remaining 'soft' donor sites in $\mathbf{5}$, the sulfur atoms S25 and S45, for an additional coordination of a 'soft' metal ion such as $\mathrm{Ag}^{+}$failed. A simultaneous reaction of $\mathrm{H}_{2} \mathrm{~L}^{\mathrm{a}}$ with $\mathrm{AgNO}_{3}$ (2 eq.) and $\mathrm{Ni}\left(\mathrm{NO}_{3}\right)_{2}$ (1 eq.), however, resulted in the formation of a yellow-green, crystalline solid of the composition $\left[\mathrm{NiAg}_{2}\left(\mathrm{~L}^{\mathrm{a}}\right)_{2}\right](\mathbf{6})$ in high yields. The ESI+ mass spectrum of the product revealed the presence of both metal ions by an intense peak at $\mathrm{m} / \mathrm{z}=1061.0121$ which can be assigned to $\left[\mathrm{Ag}_{2} \mathrm{Ni}\left(\mathrm{L}^{\mathrm{a}}\right)_{2}+\mathrm{H}\right]^{+}$fragments. The IR spectrum of 6 indicates a $\left\{\mathrm{L}^{\mathrm{a}}\right\}^{2-}$ ligand, which is coordinated without being involved into $S, O$-chelate rings with extended delocalization of $\pi$-electron density.

Single crystals of a $\mathrm{CHCl}_{3} / \mathrm{H}_{2} \mathrm{O}$ solvate of $\left[\mathrm{Ag}_{2} \mathrm{Ni}\left(\mathrm{L}^{\mathrm{a}}\right)_{2}\right]_{\infty}$ have been obtained from the reaction mixture. The quality of the derived crystallographic data was not suitable to discuss details of bond lengths and angles, but was sufficient to derive all principal structural features of the compound. The molecular structure of 6 reveals a polymeric structure consisting of helical chains with neutral, heterotrinuclear $\left[\mathrm{NiAg}_{2}\left(\mathrm{~L}^{\mathrm{a}}\right)_{2}\right]$ subunits (Fig. 5). In each subunit, the three metal ions are 
a)

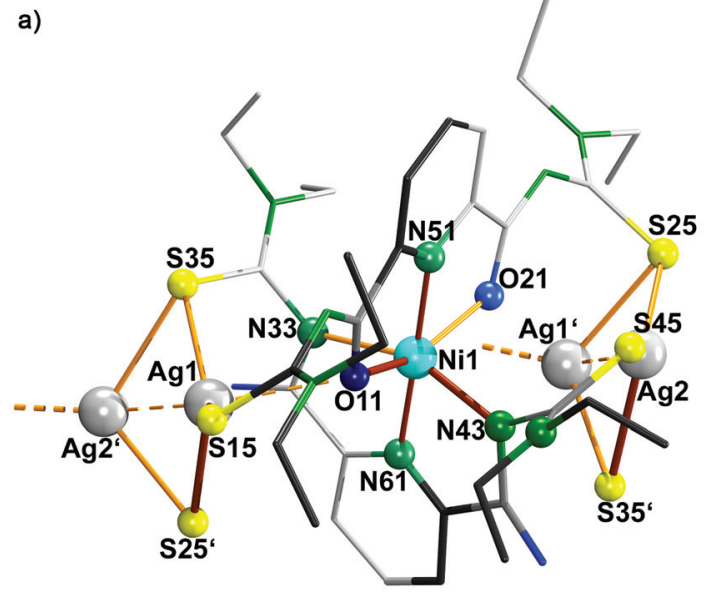

b)

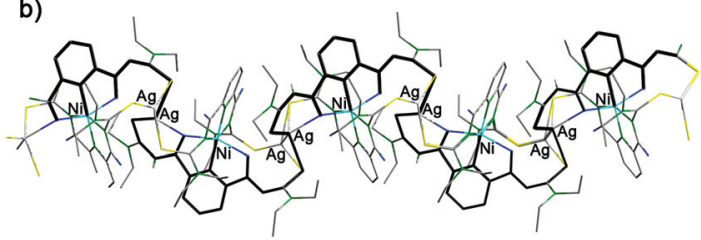

Fig. 5 Molecular structure (a) and helical polymer (b) of $\left[\mathrm{NiAg}_{2}\left(\mathrm{~L}^{\mathrm{a}}\right)_{2}\right]$ (6). ${ }^{37}$

bridged by $\left\{\mathrm{L}^{\mathrm{a}}\right\}^{2-}$ ligands. The two ligands, one with $\{\mathrm{O}, \mathrm{N}, \mathrm{O}\}$ and the other with $\{\mathrm{N}, \mathrm{N}, \mathrm{N}\}$ donor atom set, bind meridionally to the $\mathrm{Ni}^{2+}$ ion and, thus, form a distorted octahedral ligand sphere. Each of the $\mathrm{Ag}^{+}$ions are $S$-bonded to two thiourea moieties of the same $\left[\mathrm{NiAg}_{2}\left(\mathrm{~L}^{\mathrm{a}}\right)_{2}\right]$ subunit and with one other of an adjacent $\left[\mathrm{NiAg}_{2}\left(\mathrm{~L}^{\mathrm{a}}\right)_{2}\right]$ unit. Consequently, $\left\{\mathrm{Ag}_{2} \mathrm{~S}_{4}\right\}$ units link the $\mathrm{Ni}$ chelates. The $\mathrm{Ag}$ atoms establish two short (in the range of 2.4-2.5 $\AA$ ) and one long (between 2.7 and $2.8 \AA$ ) Ag-S bonds. Additionally, $\mathrm{d}^{10}-\mathrm{d}^{10} \mathrm{Ag} \cdots \mathrm{Ag}$ contacts (between 2.85 and $2.95 \AA$ are found). These distances roughly correspond to the $\mathrm{Ag} \cdots \mathrm{Ag}$ distances in metallic silver $(2.889 \AA) .{ }^{39,40}$

The failed reactions of complex 5 with $\mathrm{Ag}^{+}$ions and the ready formation of 6 during reactions of $\mathrm{H}_{2} \mathrm{~L}^{\mathrm{a}}$ with a mixture of $\mathrm{Ni}^{2+}$ and $\mathrm{Ag}^{+}$ions indicate that obvious self-assembly is essential in the formation of the complexes. In order to test for possibilities to gain control over the compositions and the structures of the reaction products by simple concepts of Inorganic Chemistry (e.g., by Pearson's acid base concept) ${ }^{30}$ we attempted reactions of $\mathrm{H}_{2} \mathrm{~L}^{\text {a }}$ with mixtures of metal ions, where $\mathrm{Ni}^{2+}$ should be the 'softer' acid $\left(\mathrm{Ni}^{2+} / \mathrm{Pr}^{3+}\right.$ and $\left.\mathrm{Ni}^{2+} / \mathrm{Ba}^{2+}\right)$ and consequently should be directed to the sulfur atoms for coordination.

Indeed, such reactions form $S, O$ chelates with the 'softer' $\mathrm{Ni}^{2+}$, while the 'harder' metal ions $\mathrm{Pr}^{3+}$ and $\mathrm{Ba}^{2+}$ are directed to the central coordination site (Fig. 6). Charge compensation is achieved by the additional coordination of acetato ligands (in the case of the lanthanide ion) or by the formation of a tris-complex with the $\mathrm{Ba}^{2+}$ center (a structural motif that is similar to the one, which has been found for the $\mathrm{In}^{3+}$ chelate of an isophthaloylbis(thioureato) ligand). ${ }^{29}$

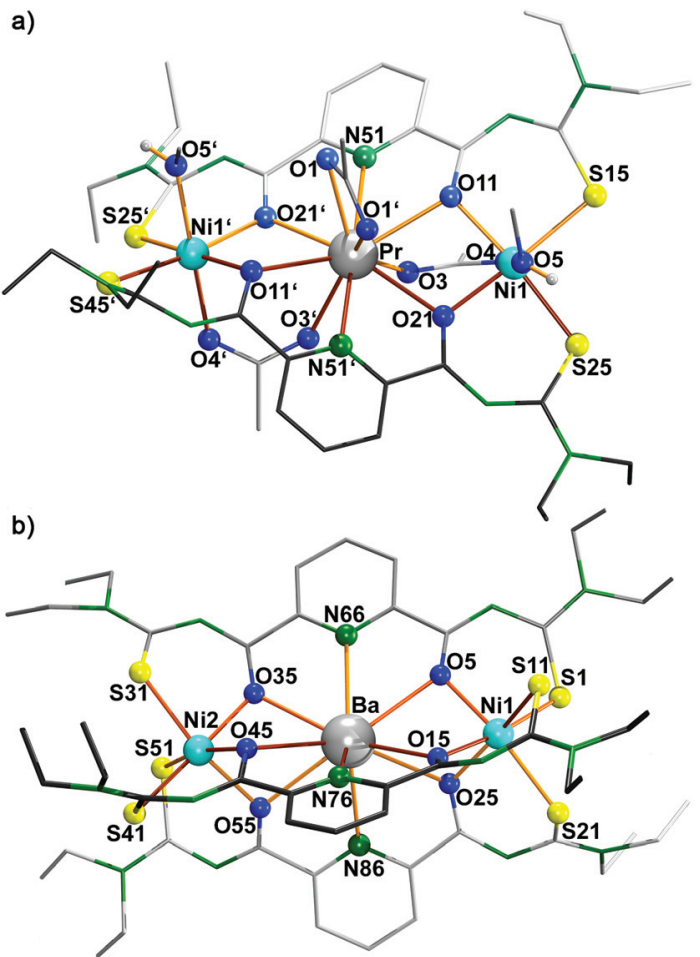

Fig. 6 Molecular structures of (a) $\left[\mathrm{Ni}_{2} \operatorname{Pr}\left(\mathrm{L}^{\mathrm{a}}\right)_{2}(\mathrm{OAc})_{3}(\mathrm{MeOH})_{2}\right](7)$ and (b) $\left[\mathrm{Ni}_{2} \mathrm{Ba}\left(\mathrm{L}^{\mathrm{a}}\right)_{3}\right](8) .{ }^{37}$

The $\mathrm{Ni}^{2+}$ ions in 7 show distorted octahedral coordination spheres, with each two cis-coordinated $S, O$ chelates in one plane, while the axial positions are occupied by oxygen atoms of the bridging acetato ligands and methanol molecules. The equatorial (chelate-bonded) coordination spheres of the nickel atoms show significant distortions from planarity and are twisted to each other by an angle of 73.25(3) ${ }^{\circ}$. The central $\mathrm{Pr}^{3+}$ ion is 10-coordinate with $\mathrm{Pr}-\mathrm{O}$ bond lengths between $2.537(2)$ and 2.580(2) $\AA$, and a Pr-N bond length of $2.643 \AA$. The coordination polyhedron of $\mathrm{Pr}^{3+}$ can best be described as a doublecapped square antiprism.

In contrast, the central $\mathrm{Ba}^{2+}$ ion in complex $\mathbf{8}$ is only ninecoordinate with an unusual coordination polyhedron, an axially bis-truncated trigonal bipyramid. This is the result of the almost planar coordination of the three $\left\{\mathrm{L}^{\mathrm{a}}\right\}^{2-}$ ligands, which is also the origin of the octahedral environment of the $\mathrm{Ni}^{2+}$ ions with facial coordination of the sulphur and oxygen atoms. The related $\mathrm{Ba}-\mathrm{O}$ and $\mathrm{Ba}-\mathrm{N}$ bond lengths are in the ranges between 2.776(1)-2.821(1) and 2.893(2)-2.928(3) $\AA$, respectively. The $\mathrm{Ni}-\mathrm{S}$ and $\mathrm{Ni}-\mathrm{O}$ bond lengths are unexceptional.

In the UV region, the spectra of $\mathrm{Ni}-\mathrm{Pr}$ and $\mathrm{Ni}-\mathrm{Ba}$ complexes show one absorption band with very high extinction coefficient at $300 \mathrm{~nm}$ which are assigned to $\pi \rightarrow \pi^{*}$ transitions. The spectrum of Ni-Ag have an additional charge transfer band at $270 \mathrm{~nm}$ region which is intensified and overlaps with the $\pi \rightarrow \pi^{*}$ band, which results in the shoulders at 278 and $312 \mathrm{~nm}$. In the visible region, the spectra of the Ni complexes show two 
weak absorption bands, one at $600-700 \mathrm{~nm}$ and the other at 900-1000 nm. These low extinction coefficient bands are commonly observed in the UV-Vis spectra of Ni(II) octahedral complexes and assigned to ${ }^{3} \mathrm{~A}_{2 \mathrm{~g}} \rightarrow{ }^{3} \mathrm{~T}_{1 \mathrm{~g}}\left({ }^{3} \mathrm{~F}\right)$ and ${ }^{3} \mathrm{~A}_{2 \mathrm{~g}} \rightarrow{ }^{3} \mathrm{~T}_{2 \mathrm{~g}}$ transitions. The band assigned to ${ }^{3} \mathrm{~A}_{2 \mathrm{~g}} \rightarrow{ }^{3} \mathrm{~T}_{1 \mathrm{~g}}\left({ }^{3} \mathrm{P}\right)$ is typically at higher energy region (around $300-350 \mathrm{~nm}$ ) is not observed. This may be the result of an overlap with the intense $\pi \rightarrow \pi^{*}$ band at $300 \mathrm{~nm}$.

The coordination environments of the $\mathrm{Pr}^{3+}$ and $\mathrm{Ba}^{2+}$ ions in the latter two complexes have features, which invite the construction of larger assemblies with the trinuclear compounds
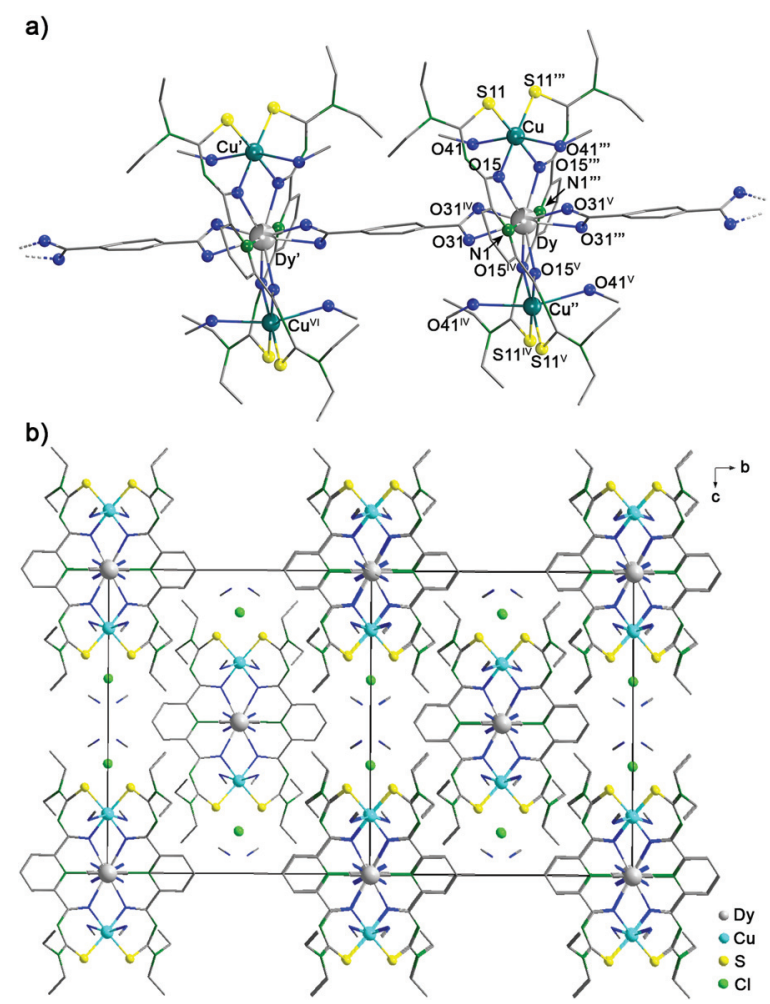

Fig. 7 (a) Molecular structure of the cationic polymer $\left[\mathrm{Cu}_{2} \mathrm{Dy}\left(\mathrm{L}^{\mathrm{a}}\right)_{2}-\right.$ $\left.\left(\mathrm{p}-\mathrm{O}_{2} \mathrm{C}-\mathrm{C}_{6} \mathrm{H}_{4}-\mathrm{CO}_{2}\right)(\mathrm{MeOH})_{4}\right]_{\infty}{ }^{\mathrm{n}+}$ (9) and (b) polymer formation along the $a$ axis. ${ }^{37}$ Symmetry operations. (') $1+x, y, z$; (") $x,-y, z$; ('") $-x,-y, z$; ('V) $x,-y,-z ;\left({ }^{V}\right)-x, y,-z ;\left({ }^{V l}\right) 1+x,-y,-z$. as building blocks. Two examples of polymers resulting from such ongoing aggregations shall be described as prototype products. They have been prepared from the replacement of the acetato ligands in compounds of type 7 by bridging terephthalates or by an extension of the coordination number of the barium ion in compounds of type 8 .

\section{Polymeric assemblies with trinuclear building blocks}

A one-pot reaction of dysprosium chloride, copper(II) chloride, terephthalic acid, $\mathrm{H}_{2} \mathrm{~L}^{\mathrm{a}}$ and $\mathrm{Et}_{3} \mathrm{~N}$ in $\mathrm{MeOH}$ gives a brown, crystalline material, which could be characterized as the polymeric compound $\left\{\left[\mathrm{Cu}_{2}^{\mathrm{II}} \mathrm{Dy}^{\mathrm{III}}\left(\mathrm{L}^{\mathrm{a}}\right)_{2}\left(\mathrm{p}-\mathrm{O}_{2} \mathrm{C}-\mathrm{C}_{6} \mathrm{H}_{4}-\mathrm{CO}_{2}\right)-(\mathrm{MeOH})_{4}\right] \mathrm{Cl}\right\}_{\infty}$ (9). The $\mathrm{Dy}^{3+}$ ions of the trinuclear $\left\{\mathrm{DyCu}_{2}\left(\mathrm{~L}^{\mathrm{a}}\right)_{2}\right\}^{3+}$ units coordinate each two terephthalato ligands, which connect the molecular subunits along the crystallographic $a$ axis. Fig. 7a shows the molecular structure of the cationic polymer. The phenyl rings of the connecting terephthalato ligands are coplanar with the Dy-N bonds. Bond lengths inside the $\left\{\mathrm{DyCu}_{2}\left(\mathrm{~L}^{\mathrm{a}}\right)_{2}\right\}^{3+}$ unit are similar to the values observed in compound 7 . The distorted octahedral coordination spheres of the copper atoms are completed by each two methanol ligands. Charge compensation is achieved by $\mathrm{Cl}^{-}$ions, which establish no contacts to the $\left[\mathrm{Cu}_{2}^{\mathrm{II}}\right.$. $\left.\mathrm{Dy}^{\mathrm{III}}\left(\mathrm{L}^{\mathrm{a}}\right)_{2}\left(\mathrm{p}-\mathrm{O}_{2} \mathrm{C}-\mathrm{C}_{6} \mathrm{H}_{4}-\mathrm{CO}_{2}\right)\right]_{\infty}{ }^{n+}$ strands. They are situated in channels, which run along the $a$ axis (Fig. 7b). These channels also contain solvent methanol.

A completely different type of polymer is formed when a mixture of $\mathrm{BaCl}_{2} \cdot 2 \mathrm{H}_{2} \mathrm{O}$ and $\mathrm{MnCl}_{2} \cdot 4 \mathrm{H}_{2} \mathrm{O}$ reacts with $\mathrm{H}_{2} \mathrm{~L}^{\mathrm{b}}$ in methanol (Scheme 2). Under the same reaction conditions, which were applied for the synthesis of compound 8, a polymeric product was obtained in favour to one with the structure of the molecular complex 8. The observed differences result from an only slight change in the backbone of the used organic ligand: $\mathrm{H}_{2} \mathrm{~L}^{\mathrm{b}}$ contains peripheral morpholinyl residues instead of ethyl groups. They can act as additional donors for 'hard' metal ions. Indeed, the coordination sphere of the $\mathrm{Ba}^{2+}$ ions, which is nine-coordinate in compound 8, was extended to ten and twelve in the two molecular sub-units of the resulting polymeric compound 10. Finally, two different trinuclear units are formed. All $\mathrm{Ba}^{2+}$ ions adopt a methanol ligand and each second of them establishes two additional bonds to the adjacent sub-units via a morpholinyl residue. This results

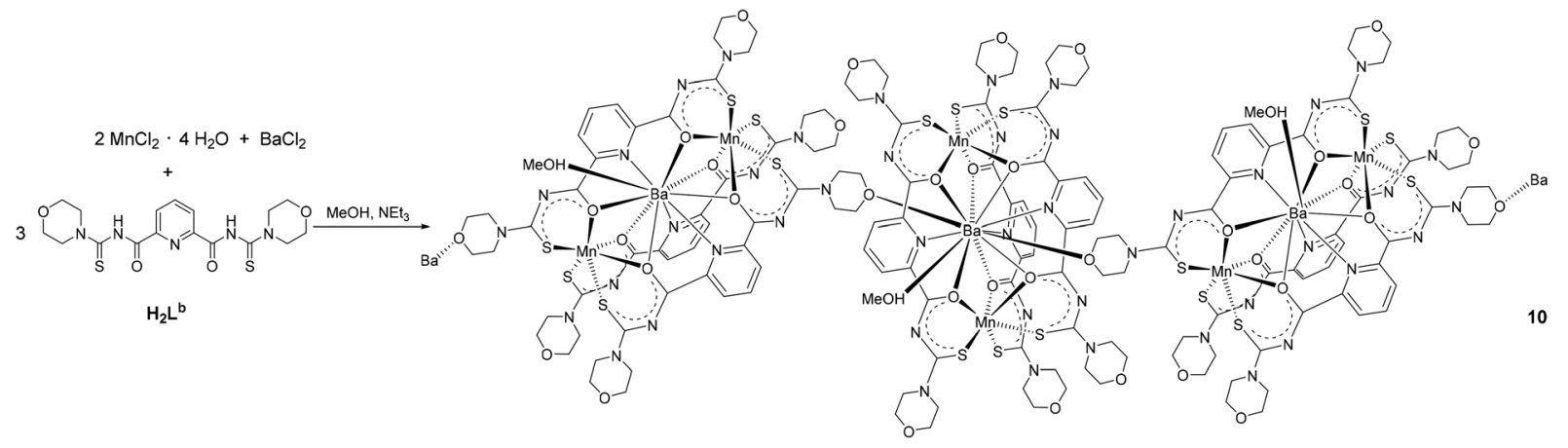

Scheme 2 Synthesis of complex 10. 
a)

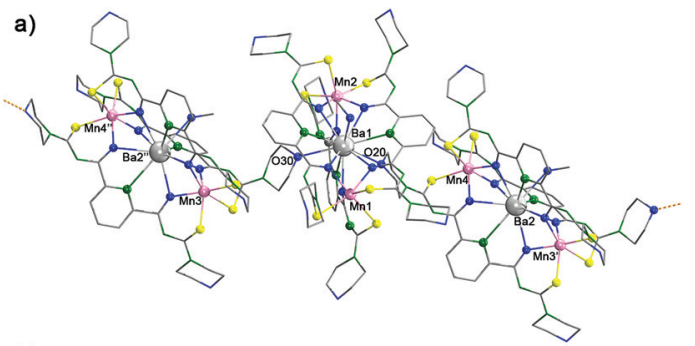

b)

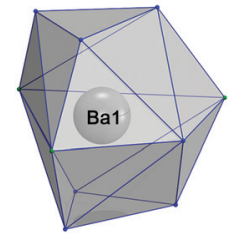

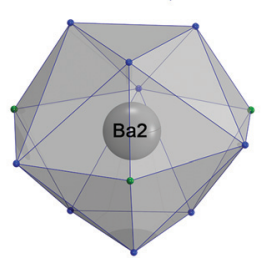

Fig. 8 (a) Chain-structure of the polymeric compound 10,37 and (b) coordination polyhedra of the $\mathrm{Ba}^{2+}$ ions. Symmetry operations: (') $x, y-$ $1, z ;(") x, y+1, z$.

in infinite zigzag chains along the crystallographic $b$ axis (see Fig. 8).

The $\mathrm{Ba}-\mathrm{O}_{\text {carbonyl }}$ bond lengths range between 2.752(1) and 2.850(1) $\AA$ in both molecules, while the $\mathrm{Ba}-\mathrm{O}_{\text {morpholine bonds }}$ of 3.029(1) and 3.084(1) $\AA$ are clearly longer. This feature characterises compound $\mathbf{1 0}$ as a typical 'supramolecular' assembly with strong and weak bonding interactions according to the definition of Lehn. ${ }^{41}$

\section{Experimental}

\section{Materials and methods}

All chemicals were reagent grade and used without further purification. Solvents were dried and used freshly distilled unless otherwise stated. The synthesis of the ligands was performed by the standard procedure. ${ }^{28}$

Infrared spectra were measured as $\mathrm{KBr}$ pellets on a Shimadzu (Japan) FTIR-spectrometer between 400 and $4000 \mathrm{~cm}^{-1}$. NMR-spectra were taken with a JEOL (Japan) $400 \mathrm{MHz}$ multinuclear spectrometer. ESI mass spectra were measured with an Agilent 6210 ESI-TOF instrument (Agilent Technology, USA). All MS results are given in the form: $m / z$, assignment. UV/Vis spectra have been recorded on a SPECORD M40 instrument (Analytik Jena, Germany). Elemental analysis of carbon, hydrogen, nitrogen, and sulfur were determined using a Heraeus (Germany) vario EL elemental analyser.

\section{Synthetic procedures}

$\left[\mathbf{N i}_{2}\left(\mathbf{L}^{\mathrm{a}}\right)_{2}(\mathbf{M e O H})\left(\mathbf{H}_{2} \mathbf{O}\right)\right](5) . \mathrm{H}_{2} \mathrm{~L}^{\mathrm{a}}(79.1 \mathrm{mg}, 0.2 \mathrm{mmol})$ was dissolved in $5 \mathrm{~mL} \mathrm{MeOH}$ and added to a stirred solution of $\mathrm{Ni}\left(\mathrm{NO}_{3}\right)_{2} \cdot 6 \mathrm{H}_{2} \mathrm{O}(59.2 \mathrm{mg}, 0.2 \mathrm{mmol})$ in $5 \mathrm{~mL} \mathrm{MeOH}$. After $5 \mathrm{~min}$, $\mathrm{Et}_{3} \mathrm{~N}(50.5 \mathrm{mg}, 0.5 \mathrm{mmol})$ was added and the reaction mixture was heated under reflux for $30 \mathrm{~min}$. The reaction mixture was reduced in volume to about $2 \mathrm{~mL}$ and stored in a freezer overnight. The precipitated pale green solid was collected by fil- tration, washed with $\mathrm{MeOH}$, and dried under vacuum. Yield $70 \%(63 \mathrm{mg})$. Elemental analysis: Calcd for $\mathrm{C}_{34} \mathrm{H}_{46} \mathrm{~N}_{10} \mathrm{O}_{4} \mathrm{~S}_{4} \mathrm{Ni}_{2}$ : C, 45.2; H, 5.1; N, 15.5; S, 14.2\%. Found: C, 45.7; H, 5.4; $\mathrm{N}, 15.1 ; \mathrm{S}, 14.2 \%$. IR (KBr, cm $\left.{ }^{-1}\right): 2974(\mathrm{~m}), 2934(\mathrm{~m}), 1624$ (m), 1564 (s), 1546 (s), 1530 (s), 1510 (m), 1494 (m), 1425 (m), 1381 (s), 1358 (m), 1312 (m), 1288 (m), 1254 (m), 1148 (w), 1099 (m), 1074 (m), 862 (w), 841 (w), 760 (m), 683 (m), 500 (w). UV-Vis $\left(\mathrm{CH}_{2} \mathrm{Cl}_{2}\right) ; \lambda_{\max }(\mathrm{nm}), \varepsilon\left(\mathrm{L} \mathrm{mol}^{-1} \mathrm{~cm}^{-1}\right): 280\left(3.9 \times 10^{4}\right)$, $315\left(2.5 \times 10^{4}\right), 680(8.8) . \mathrm{ESI}^{+} \mathrm{MS}(\mathrm{m} / \mathrm{z}): 925.1256(100 \%$ base peak, $\left.[\mathrm{M}+\mathrm{Na}]^{+}\right)$, Calcd: 925.1191 .

Single crystals for X-ray diffraction were obtained by slow evaporation of an acetone/MeOH $1: 1(\mathrm{v} / \mathrm{v})$ solution at room temperature.

$\left[\mathrm{Ag}_{2} \mathrm{Ni}\left(\mathrm{L}^{\mathrm{a}}\right)_{2}\right]_{\infty}$ (6). $\mathrm{Ni}\left(\mathrm{NO}_{3}\right)_{2} \cdot 6 \mathrm{H}_{2} \mathrm{O}(29.6 \mathrm{mg}, 0.1 \mathrm{mmol})$ and $\mathrm{AgNO}_{3}(34.0 \mathrm{mg}, 0.2 \mathrm{mmol}$ ) were dissolved in $5 \mathrm{~mL} \mathrm{MeOH}$ and $\mathrm{H}_{2} \mathrm{~L}^{\mathrm{a}}$ (79.1 $\mathrm{mg}, 0.2 \mathrm{mmol}$ ) in $5 \mathrm{~mL} \mathrm{CH}_{2} \mathrm{Cl}_{2}$ was added. The mixture was stirred for 3-5 min at room temperature and then $\mathrm{Et}_{3} \mathrm{~N}(50.5 \mathrm{mg}, 0.5 \mathrm{mmol})$ was added. Upon the addition of $\mathrm{Et}_{3} \mathrm{~N}$, the colour of the solution turned from light green to deep yellow-green. The mixture was allowed to evaporate slowly at room temperature. After several days, a few yellow-green single crystals deposited which were suitable for X-ray structure analysis. Further concentration of the remaining solution gave more product in the form of an analytically pure powder, which was washed twice with $\mathrm{MeOH}$ and dried in vacuum. Yield 85\% (90 mg). Elemental analysis: Calcd for $\mathrm{C}_{34} \mathrm{H}_{46} \mathrm{~N}_{10} \mathrm{O}_{4}$ $\mathrm{S}_{4} \mathrm{Ag}_{2} \mathrm{Ni}$ : C, 38.5; H, 4.4; N, 13.2; S, 12.1\%. Found: C, 38.6; H, 4.5; N, 13.2; S, 12.0\%. IR (KBr, $\left.\mathrm{cm}^{-1}\right): 2974(\mathrm{w}), 2933(\mathrm{w}), 1623$ (m), 1550 (s), 1498 (m), 1425 (s), 1357 (m), 1311 (m), 1238 (s), 1145 (w), 1109 (w), 1074 (w), 756 (m), 683 (m). UV-Vis $\left(\mathrm{CH}_{2} \mathrm{Cl}_{2} /\right.$ EtOH) $(1: 1, \mathrm{v} / \mathrm{v}) ; \lambda_{\max }(\mathrm{nm}), \varepsilon\left(\mathrm{L} \mathrm{mol}^{-1} \mathrm{~cm}^{-1}\right): 278\left(3.7 \times 10^{4}\right)$; $312\left(3.36 \times 10^{4}\right) ; 589$ (27.8); 976 (82.5). ESI $^{+}$MS $(m / z)$ : 1061.0121 (100\% base peak, $\left.[\mathrm{M}+\mathrm{H}]^{+}\right)$, Calcd: 1061.0117 .

$\left[\mathrm{Ni}_{2} \mathbf{P r}\left(\mathbf{L}^{\mathbf{a}}\right)_{2}(\mathbf{O A c})_{3}(\mathbf{M e O H})_{2}\right] \quad(7) . \quad \mathrm{Ni}(\mathrm{OAc})_{2} \cdot 4 \mathrm{H}_{2} \mathrm{O} \quad(49.8 \mathrm{mg}$, $0.2 \mathrm{mmol})$ and $\mathrm{PrCl}_{3} \cdot 7 \mathrm{H}_{2} \mathrm{O}(0.1 \mathrm{mmol})$ were dissolved in $5 \mathrm{~mL}$ $\mathrm{MeOH}$ and solid $\mathrm{H}_{2} \mathrm{~L}^{\mathrm{a}}$ (79.1 $\mathrm{mg}, 0.2 \mathrm{mmol}$ ) was added. The mixture was stirred for $5 \mathrm{~min}$ at room temperature and then $\mathrm{Et}_{3} \mathrm{~N}$ (50.5 mg, $0.5 \mathrm{mmol}$ ) was added. The resulting solution was heated under reflux for $60 \mathrm{~min}$. After cooling to room temperature, a green-yellow solid was collected by suction filtration, washed with $\mathrm{MeOH}$, and dried in vacuum. The analytically pure powder was used for physical measurements. Yield 83\% (100 mg). Elemental analysis: Calcd for $\mathrm{C}_{40} \mathrm{H}_{55} \mathrm{~N}_{10} \mathrm{O}_{10} \mathrm{~S}_{4} \mathrm{Ni}_{2} \mathrm{Pr}$ : C, 39.3; H, 4.5; N, 11.5, S, 10.5\%. Found: C, 39.2; H, 4.6; N, 11.4; S, 10.5\%. IR (KBr, cm $\left.{ }^{-1}\right): 2981(\mathrm{~m}), 2931(\mathrm{w}), 2873(\mathrm{w})$, 1547 (vs), 1511 (vs), 1426 (s), 1390 (s), 1354 (m), 1251 (m), 1077 (w), $850(\mathrm{w}), 758(\mathrm{~m}), 659(\mathrm{~m})$. UV-Vis $\left(\mathrm{CH}_{2} \mathrm{Cl}_{2} / \mathrm{EtOH}\right)(1: 1$, $\mathrm{v} / \mathrm{v}) ; \lambda_{\max }(\mathrm{nm}), \varepsilon\left(\mathrm{L} \mathrm{mol}^{-1} \mathrm{~cm}^{-1}\right): 297\left(5.35 \times 10^{4}\right) ; 681$ (33.6); 926 (23.5). $\mathrm{ESI}^{+} \mathrm{MS}(\mathrm{m} / \mathrm{z}): 1161.0642$ (100\% base peak, $\left.\left[\mathrm{M}-\mathrm{CH}_{3} \mathrm{COO}^{-}\right]^{+}\right)$, Calcd: 1161.0636. Single crystals for X-ray structure analysis were obtained by recrystallization from $\mathrm{CH}_{2} \mathrm{Cl}_{2} / \mathrm{MeOH}(1: 1, \mathrm{v} / \mathrm{v})$.

$\left[\mathrm{Ni}_{2} \mathbf{B a}\left(\mathbf{L}^{\mathrm{a}}\right)_{3}\right](\mathbf{8}) \cdot \mathrm{H}_{2} \mathrm{~L}^{\mathrm{a}}(118.6 \mathrm{mg}, 0.3 \mathrm{mmol})$ was added to a solution of $\mathrm{Ni}(\mathrm{OAc})_{2} \cdot 4 \mathrm{H}_{2} \mathrm{O}(49.8 \mathrm{mg}, \quad 0.2 \mathrm{mmol})$ and $\mathrm{BaCl}_{2} \cdot 2 \mathrm{H}_{2} \mathrm{O}(24.5 \mathrm{mg}, 0.1 \mathrm{mmol})$ in $5 \mathrm{~mL} \mathrm{MeOH}$. The mixture was stirred for $5 \mathrm{~min}$ at room temperature and then $\mathrm{Et}_{3} \mathrm{~N}$ 
(50.5 mg, $0.5 \mathrm{mmol}$ ) was added. The resulting solution was stirred for $30 \mathrm{~min}$ at $40{ }^{\circ} \mathrm{C}$. The obtained brown precipitate was filtered off, washed with $\mathrm{MeOH}$, and dried under vacuum. Elemental analysis: Calcd for $\mathrm{C}_{51} \mathrm{H}_{69} \mathrm{BaN}_{15} \mathrm{Ni}_{2} \mathrm{O}_{6} \mathrm{~S}_{6}$ : C, 42.7; H, 4.8; N, 14.6; S, 13.4\%, Found: C, 42.7; H, 4.6; N, 14.5; S, 13.4\%. IR (KBr, $\left.\mathrm{cm}^{-1}\right): 2975$ (m), $2950(\mathrm{~m}), 2868(\mathrm{w}), 1580$ (vs), 1555 (vs), 1493 (s), 1440 (s), 1410 (s), 1357 (s), 1270 (m), $1148(\mathrm{~m}), 1066(\mathrm{~m}), 750(\mathrm{~m})$. UV-Vis $\left(\mathrm{CH}_{2} \mathrm{Cl}_{2} / \mathrm{EtOH}\right)(1: 1, \mathrm{v} / \mathrm{v})$; $\lambda_{\max }(\mathrm{nm}), \varepsilon\left(\mathrm{L} \mathrm{mol}{ }^{-1} \mathrm{~cm}^{-1}\right)$ : $305\left(1.03 \times 10^{5}\right) ; 701$ (58.7); 1020 (34.8). $\mathrm{ESI}^{+}$MS: $\mathrm{m} / \mathrm{z}=1434.1683$ (100\% base peak, $\left.[\mathrm{M}+\mathrm{H}]^{+}\right)$, Calcd: 1434.1717 .

Single crystals for X-ray diffraction were obtained from slow evaporation of a $\mathrm{CH}_{2} \mathrm{Cl}_{2} / \mathrm{MeOH}$ mixture $(1: 1, \mathrm{v} / \mathrm{v})$.

$\left\{\left[\mathrm{Cu}_{2} \mathrm{Dy}\left(\mathrm{L}^{\mathrm{a}}\right)_{2}\left(\mathrm{p}-\mathrm{O}_{2} \mathrm{C}-\mathrm{C}_{6} \mathrm{H}_{4}-\mathrm{CO}_{2}\right)\right] \mathrm{Cl}\right\}_{\infty}$ (9). $\mathrm{CuCl}_{2} \cdot 2 \mathrm{H}_{2} \mathrm{O}(35 \mathrm{mg}$, $0.2 \mathrm{mmol})$ and $\mathrm{DyCl}_{3} \cdot 6 \mathrm{H}_{2} \mathrm{O}(38 \mathrm{mg}, 0.1 \mathrm{mmol})$ were dissolved in $5 \mathrm{~mL} \mathrm{MeOH}$ and solid $\mathrm{H}_{2} \mathrm{~L}^{\mathrm{a}}(79 \mathrm{mg}, 0.2 \mathrm{mmol}$ ) and terephthalic acid (17 mg, $0.1 \mathrm{mmol}$ ) were added. The mixture was stirred for $5 \mathrm{~min}$ at room temperature and then $\mathrm{Et}_{3} \mathrm{~N}(50.5 \mathrm{mg}$, $0.5 \mathrm{mmol}$ ) was added. The resulting solution was heated under reflux for $60 \mathrm{~min}$. Very slow evaporation of the resulting clear solution gave brown, almost insoluble crystals, which were suitable for X-ray diffraction. Yield $65 \%(100 \mathrm{mg})$. Elemental analysis: Calcd for $\mathrm{C}_{48} \mathrm{H}_{74} \mathrm{~N}_{10} \mathrm{O}_{14} \mathrm{~S}_{4} \mathrm{Cu}_{2}$ DyCl: C, 39.3; H, 5.0; N, 9.5, S, 8.7\%. Found: C, 39.2; H, 4.8; N, 9.3; S, 8.5\%. IR (KBr, cm $\left.{ }^{-1}\right)$ : $3001(\mathrm{~m}), 2925(\mathrm{w}), 2868$ (w), 1535 (vs), 1506 (vs), 1426 (s), 1389 (s), 1354 (m), 1246 (m), 1081 (w), $845(\mathrm{w}), 755(\mathrm{~m}), 659(\mathrm{~m})$.

$\left[\mathbf{M n}_{2} \mathbf{B a}(\mathbf{M e O H})\left(\mathbf{L}^{\mathrm{b}}\right)_{3}\right]_{\infty}(\mathbf{1 0}) . \mathrm{H}_{2} \mathrm{~L}^{\mathrm{b}}(127.1 \mathrm{mg}, 0.3 \mathrm{mmol})$ was added to a solution of $\mathrm{MnCl}_{2} \cdot 4 \mathrm{H}_{2} \mathrm{O}(39.6 \mathrm{mg}, 0.2 \mathrm{mmol})$ and $\mathrm{BaCl}_{2} \cdot 2 \mathrm{H}_{2} \mathrm{O}(24.5 \mathrm{mg}, 0.1 \mathrm{mmol})$ in $5 \mathrm{~mL} \mathrm{MeOH}$. The mixture was stirred for $5 \mathrm{~min}$ at room temperature and then $\mathrm{Et}_{3} \mathrm{~N}$ (50.5 mg, $0.5 \mathrm{mmol}$ ) was added. The resulting solution was stirred for $30 \mathrm{~min}$ at $40^{\circ} \mathrm{C}$. Upon cooling, a yellow solid started to precipitate. The almost insoluble solid was filtered off and washed with methanol. The mother liquor was mixed with $2 \mathrm{~mL} \mathrm{CH}_{2} \mathrm{Cl}_{2}$ and stored in a refrigerator for crystallization. Yellow single crystals of the $\mathrm{CH}_{2} \mathrm{Cl}_{2} / \mathrm{MeOH} / \mathrm{H}_{2} \mathrm{O}$ solvate could be isolated after a period of two weeks. Overall yield 95\% (144 mg). Elemental analysis of the powdered and carefully dried sample: Calcd for $\mathrm{C}_{52} \mathrm{H}_{61} \mathrm{BaMn}_{2} \mathrm{~N}_{15} \mathrm{O}_{13} \mathrm{~S}_{6}: \mathrm{C}, 40.5 ; \mathrm{H}, 4.0$; N, 16.6; S, 12.5\%, Found: C, 40.7; H, 4.8; N, 15.9; S, 12.7\%. IR (KBr, cm $\left.{ }^{-1}\right)$ : $2964(\mathrm{~m}), 2940(\mathrm{~m}), 2871$ (w), 1575 (vs), 1547 (vs), 1482 (s), 1445 (s), 1418 (s), 1356 (s), 1270 (m), 1152 (m), 1059 (m), 752 (m).

\section{Crystallography}

The intensities for the $\mathrm{X}$-ray determinations of $\left[\mathrm{Ni}_{2}\left(\mathrm{~L}^{\mathrm{a}}\right)_{2}(\mathrm{MeOH})\left(\mathrm{H}_{2} \mathrm{O}\right)\right] \quad(5) \cdot$ acetone $\cdot \mathrm{MeOH} \cdot \mathrm{H}_{2} \mathrm{O}, \quad\left\{\left[\mathrm{Ag}_{2} \mathrm{Ni}\left(\mathrm{L}^{\mathrm{a}}\right)_{2}\right]\right.$ (6) $\left.\cdot \mathrm{CHCl}_{3} \cdot 1.5 \mathrm{H}_{2} \mathrm{O}\right\}_{\infty}, \quad\left[\mathrm{Ni}_{2} \mathrm{Pr}\left(\mathrm{L}^{\mathrm{a}}\right)_{2}(\mathrm{OAc})_{3}(\mathrm{MeOH})_{2}\right] \quad(7) \cdot 2 \mathrm{MeOH}$, $\left\{\left[\mathrm{Cu}_{2} \mathrm{Dy}\left(\mathrm{L}^{\mathrm{a}}\right)_{2}\left(\mathrm{p}-\mathrm{O}_{2} \mathrm{C}-\mathrm{C}_{6} \mathrm{H}_{4}-\mathrm{CO}_{2}\right)(\mathrm{MeOH})_{4}\right] \mathrm{Cl}\right\}_{\infty} \quad(\mathbf{9}) \cdot 2 \mathrm{MeOH}$ and $\left[\mathrm{Mn}_{2} \mathrm{Ba}(\mathrm{MeOH})\left(\mathrm{L}^{\mathrm{b}}\right)_{3}\right]_{\infty}(\mathbf{1 0}) \cdot 2 \mathrm{CH}_{2} \mathrm{Cl}_{2} \cdot \mathrm{MeOH} \cdot 4.5 \mathrm{H}_{2} \mathrm{O}$ were collected on a STOE (Germany) IPDS $2 \mathrm{~T}$ instrument at $200 \mathrm{~K}$ with Mo Ko radiation $(\lambda=0.71073 \AA)$ using a graphite monochromator. The intensities for the X-ray determination of $\left[\mathrm{Ni}_{2} \mathrm{Ba}\left(\mathrm{L}^{\mathrm{a}}\right)_{3}\right](8)$ were collected on a D8 QUEST Bruker (Germany) instrument at $100 \mathrm{~K}$ with Mo K $\alpha$ radiation $(\lambda=0.71073 \AA$ Å) using a TRIUMPH

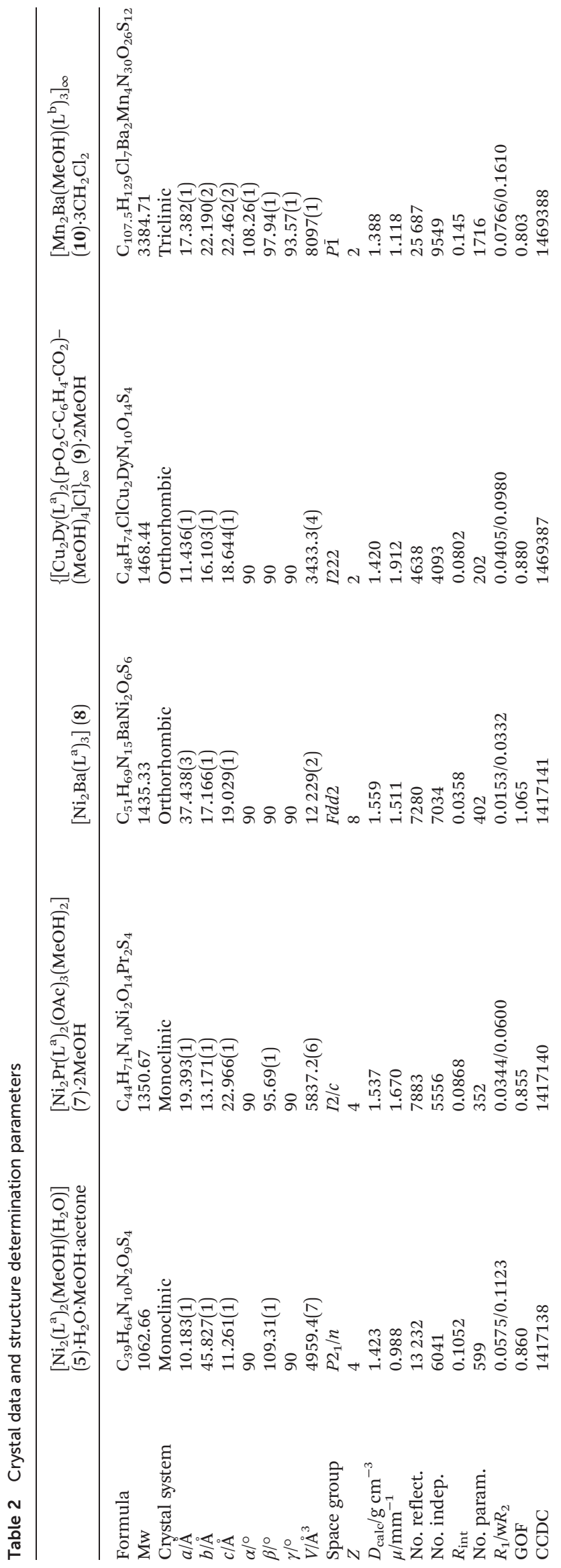


monochromator. Standard procedures were applied for data reduction and absorption correction. Structure solution and refinements were performed with SHELX. ${ }^{42}$ Hydrogen atom positions were calculated for idealized positions and treated with the 'riding model' option of SHELXL (Table 2).

Additional information on the structure determinations has been deposited with the Cambridge Crystallographic Data Centre.

\section{Computational details}

The gas phase geometries of the isomers of the compound 5 were optimized without any symmetry restrictions by the DFT method with the exchange correlation functional PBE1PBE, using the Gaussian-09 Revision D.01 program package. ${ }^{38}$ Ground spin state of each isomer was determined taking account of the electronic properties and the coordination geometry of the $\mathrm{Ni}^{2+}$ ions in the particular complex (Table 1 ). The initial geometry used for the optimization of the compound 5 was based on crystal structure parameters, while the initial geometry of the isomers $5^{\prime}, 5^{\prime \prime}$ and $\mathbf{5}^{\prime \prime \prime}$ was obtained by modifications of the crystal structure of the $\mathrm{Ni}$ (II) binuclear complex of isophthaloyl( $N, N$-diethylthiourea), which was previously reported. ${ }^{28}$ The calculations were performed using the LANL2TZ basis set obtained from the EMSL Basis Set Library for $\mathrm{Ni}^{43,44}$ the $6-311 \mathrm{G}^{*}$ basis sets for $\mathrm{C}, \mathrm{O}, \mathrm{N}, \mathrm{S}$ and the $6-311 \mathrm{G}$ basis set for $\mathrm{H}^{43,44}$ The optimized geometries were verified by performing frequency calculations. The absence of an imaginary frequency ensures that the optimized geometries correspond to true energy minima. Energy values were corrected by Zero Point Energy (ZPE). All theoretical calculations were carried out with the high-performance computing system of ZEDAT, Freie Universität Berlin, (https://www.zedat.fu-berlin. de/HPC/Home).

\section{Conclusions}

2,6-Dipicolinoylbis( $N, N$-dialkylthioureas) represent a class of ligands which forms metal complexes with a wide structural variety. The presence of soft, borderline, and hard donor atoms particularly recommends them for the assembly of mixed-metal complexes with appropriate metal ions. This has been demonstrated for a number of oligonuclear compounds. Suitable substitutions in the peripheries of the ligands and/or the combination with co-ligands allow further aggregation of the oligonuclear sub-units and the formation of coordination polymers as has been demonstrated with a bridging dicarboxylate as well as with the introduction of a weakly coordinating donor site as the morpholinyl residue.

Fig. 9 illustrates some prospective derivatives of $\mathrm{H}_{2} \mathrm{~L}$, which may give access to one-, two- or three-dimensional networks on the basis of coordinate bonds of variable strengths. This can be controlled by variation either of the nature of the donor atoms or their position in the molecular framework (compounds 11-13). The extension of the "thiourea" chemistry to corresponding ligands possessing aroylselenourea donor sets

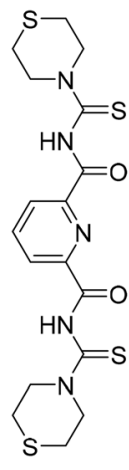

11

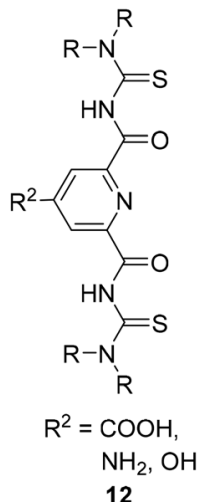

12

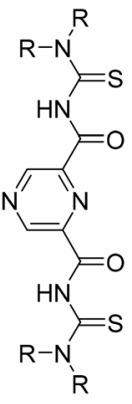

13<smiles>[R]NC(=[Se])NC(=O)c1cccc(C(=O)NC([Se])N([R])[R])n1</smiles>

14
Fig. 9 Prospective aroylchalcogenourea ligands for the setup of polymeric complexes.

(compound 14) will allow an even better differentiation of metal ions with regard to their "softness".

\section{Acknowledgements}

We gratefully acknowledge financial support from the MOET (Vietnam) through 911 Program and the DAAD (Germany).

\section{Notes and references}

1 T. R. Cook, Y.-R. Zheng and P. J. Stang, Chem. Rev., 2013, 113, 734 .

2 K. Rissanen, L. J. Barbour and L. R. McGillivray, CrystEngComm, 2014, 16, 3644.

3 B. Schulze and U. S. Schubert, Chem. Soc. Rev., 2014, 43, 2522.

4 T. Müller and S. Bräse, RSC Adv., 2014, 4, 6886.

5 E. C. Constable, Chem. Soc. Rev., 2013, 42, 1637.

6 R. W. Saalfrank and A. Scheurer, Top. Curr. Chem., 2012, 319, 125.

7 J.-M. Lehn, C. R. Chim., 2011, 14, 348.

8 G. Aromi, P. Gamez and J. Reedijk, Coord. Chem. Rev., 2008, 252, 964.

9 R. W. Saalfrank, H. Maid and A. Scheurer, Angew. Chem., Int. Ed., 2008, 47, 879.

10 S. Leininger, B. Olenyuk and P. J. Stang, Chem. Rev., 2000, 100, 853.

11 M. Fujita, K. Umemoto, M. Yishizawa, N. Fujita, T. Kusukawa and K. Biradha, Chem. Commun., 2001, 509.

12 D. L. Caulder and K. Raymond, J. Chem. Soc., Dalton Trans., 1999, 1185.

13 F. A. Cotton, C. Lin and C. A. Murillo, Acc. Chem. Res., 2001, 34, 759.

14 N. C. Ganneschi, M. S. Masar and C. A. Mirkin, Acc. Chem. Res., 2005, 38, 759.

15 Y. K. Kryshenko, S. R. Seidel, A. M. Arif and P. J. Stang, J. Am. Chem. Soc., 2003, 125, 5193.

16 F. A. Cotton, C. Lin and C. A. Murillo, Inorg. Chem., 2001, 40, 478. 
17 D. L. Caulder, R. E. Powers, T. N. Parac and K. N. Raymond, Angew. Chem., Int. Ed., 1998, 37, 1840.

18 M. Fujita, D. Oguro, M. Miyazawa, H. Oka, K. Yamaguchi and K. Ogura, Nature, 1995, 378, 469.

19 L. Beyer, E. Hoyer, J. Liebscher and H. Hartmann, Z. Chem., 1981, 21, 228.

20 R. K. Koch, Coord. Chem. Rev., 2001, 216-217, 473.

21 W. Zhou, Y. Wen, L. Qiu, Y. Zhang and Z. Yu, J. Mol. Struct., 2005, 749, 89.

22 M. Kampf, R. Richter, S. Gerber and R. Kirmse, Z. Anorg. Allg. Chem., 2004, 630, 1437.

23 T. J. Egan, K. R. Koch, P. L. Swan, C. Clarkson, D. A. van Schalkwyk and P. J. Smith, J. Med. Chem., 2004, 47, 2926.

24 K. R. Koch, S. A. Bourne, A. Coetzee and J. Miller, J. Chem. Soc., Dalton Trans., 1999, 3157.

25 O. Hallale, S. A. Bourne and K. R. Koch, CrystEngComm, 2005, 7, 161.

26 O. Hallale, S. A. Bourne and K. R. Koch, New J. Chem., 2005, 29, 1416.

27 A. N. Westra, S. A. Bourne and K. R. Koch, Dalton Trans., 2005, 2916.

28 A. Rodenstein, J. Griebel, R. Richter and R. Kirmse, Z. Anorg. Allg. Chem., 2008, 634, 867.

29 V. D. Schwade, L. Kirsten, A. Hagenbach, E. Schulz Lang and U. Abram, Polyhedron, 2013, 55, 155.

30 H. H. Nguyen, C. T. Pham, A. Rodenstein, R. Kirmse and U. Abram, Inorg. Chem., 2011, 50, 590.

31 T. A. Wioppiold, J. Ackermann, E. Schulz Lang and U. Abram, Polyhedron, 2015, 87, 202.

32 R. G. J. Pearson, Am. Chem. Soc., 1963, 85, 3533.

33 U. Schröder, L. Beyer and J. Sieler, Inorg. Chem. Commun., 2000, 3, 630.

34 U. Braun, R. Richter, J. Sieler, A. I. Yanovsky and Y. T. Struchkov, Z. Anorg. Allg. Chem., 1985, 529, 201.
35 K. R. Koch and S. Bourne, J. Mol. Struct., 1998, 441, 11.

36 N. H. Huy and U. Abram, Inorg. Chem., 2007, 46, 5310.

37 K. Brandenburg, DIAMOND, vers. 3.2i, Crystal Impact GbR, Bonn, Germany.

38 M. J. Frisch, G. W. Trucks, H. B. Schlegel, G. E. Scuseria, M. A. Robb, J. R. Cheeseman, G. Scalmani, V. Barone, B. Mennucci, G. A. Petersson, H. Nakatsuji, M. Caricato, X. Li, H. P. Hratchian, A. F. Izmaylov, J. Bloino, G. Zheng, J. L. Sonnenberg, M. Hada, M. Ehara, K. Toyota, R. Fukuda, J. Hasegawa, M. Ishida, T. Nakajima, Y. Honda, O. Kitao, H. Nakai, T. Vreven, J. A. Montgomery Jr., J. E. Peralta, F. Ogliaro, M. Bearpark, J. J. Heyd, E. Brothers, K. N. Kudin, V. N. Staroverov, T. Keith, R. Kobayashi, J. Normand, K. Raghavachari, A. Rendell, J. C. Burant, S. S. Iyengar, J. Tomasi, M. Cossi, N. Rega, J. M. Millam, M. Klene, J. E. Knox, J. B. Cross, V. Bakken, C. Adamo, J. Jaramillo, R. Gomperts, R. E. Stratmann, O. Yazyev, A. J. Austin, R. Cammi, C. Pomelli, J. W. Ochterski, R. L. Martin, K. Morokuma, V. G. Zakrzewski, G. A. Voth, P. Salvador, J. J. Dannenberg, S. Dapprich, A. D. Daniels, O. Farkas, J. B. Foresman, J. V. Ortiz, J. Cioslowski and D. J. Fox, Gaussian 09, Revision D.01, Gaussian, Inc., Wallingford CT, 2013.

39 K. Singh, J. R. Long and P. Stavropoulos, J. Am. Chem. Soc., 1997, 119, 2942.

40 N. C. Baenziger and A. W. Struss, Inorg. Chem., 1976, 15, 1807.

41 J. M. Lehn, Science, 1993, 260, 1762.

42 G. M. Sheldrick, Acta Crystallogr., Sect. C: Cryst. Struct. Commun., 2015, 7, 3.

43 D. Feller, J. Comput. Chem., 1996, 17, 1571.

44 K. L. Schuchardt, B. T. Didier, T. Elsethagen, L. Sun, V. Gurumoorthi, J. Chase, J. Li and T. L. Windus, J. Chem. Inf. Model., 2007, 47, 1045. 